\title{
Fast 2D MRI acquisitions for motion correction in PET-MRI
}

\author{
Michael Fieseler ${ }^{1,2^{*}}$, Christopher Glielmi ${ }^{4}$, Thomas Kösters ${ }^{3}$, Lynn Frohwein ${ }^{1}$, Fernado Boada ${ }^{3}$, Xiaoyi Jiang ${ }^{1,2}$, \\ Klaus P Schäfers ${ }^{1}$ \\ From PSMR14: 3rd Conference in PET/MR and SPECT/MR \\ Kos Island, Greece. 19-21 May 2014
}

${ }^{1}$ European Institute for Molecular Imaging, University of Münster, Münster, Germany
We performed continuous, fast acquisitions of 2D MR slices covering the thorax under free breathing.

In present work, acquired 2D stacks are re-stored using a respiration signal. The usage of $2 \mathrm{D}$ slices is similar to the method described in [1]. The proposed method, however, does not include a navigator and acquisition times are shorter.

Dara were acquired from two patients on a Siemens Biograph mMR scanner (Siemens Healthcare, Erlangen, Germany) using a FLASH sequence, TE $1.38 \mathrm{~ms}$, TR 26ms, flip angle 12o, a 32-channel body-coil (acceleration factor of 8).

20 coronal slices were acquired with $3.9 \times 6.25 \mathrm{~mm} 2$ in-plane resolution (HF, LR), $128 \times 128$ pixel, slice thickness $9 \mathrm{~mm}$, slice spacing $9 \mathrm{~mm}, 26 \mathrm{~ms}$ per $2 \mathrm{D}$ slice (total acquisition time 160s).

A respiratory signal was estimated from affine registrations of an area showing respiratory motion and subsequently used to sort the acquired 2D stacks into 8 respiratory phases.

Figure 1 shows input data and re-gated data. Noise is reduced by averaging of several 2D stacks. Additionally, cardiac motion is eliminated to a large extent, thus the generated dataset can be used for respiratory motion correction. Average correlation of 2D stacks assigned to a phase is 0.958 for dataset 1 (randomly selected gates: 0.933 , SD 0.03). For dataset 2 the average correlation of $2 \mathrm{D}$ stacks assigned to a phase is 0.94 (randomly selected gates: 0.9 , SD 0.036).

The results indicate that the proposed method is suitable for use in respiratory motion correction of PET data. In future work we will evaluate our approach on more datasets. Additionally, we will use motion estimates for each acquired 2D image stack to correct motion frame-wise.

\section{Authors' details}

${ }^{1}$ European Institute for Molecular Imaging, University of Münster, Münster, Germany. ${ }^{2}$ Department of Computer Science, University of Münster, Münster, Germany. ${ }^{3}$ Center for Advanced Imaging Innovation and Research, NYU Langone Medical Center, New York, USA. ${ }^{4}$ Siemens Medical Solutions USA, New York, USA.

Published: 29 July 2014

\section{SpringerOpen ${ }^{\circ}$}

(c) 2014 Fieseler et al; licensee Springer This is an Open Access article distributed under the terms of the Creative Commons Attribution License (http://creativecommons.org/licenses/by/4.0), which permits unrestricted use, distribution, and reproduction in any medium, provided the original work is properly cited. 


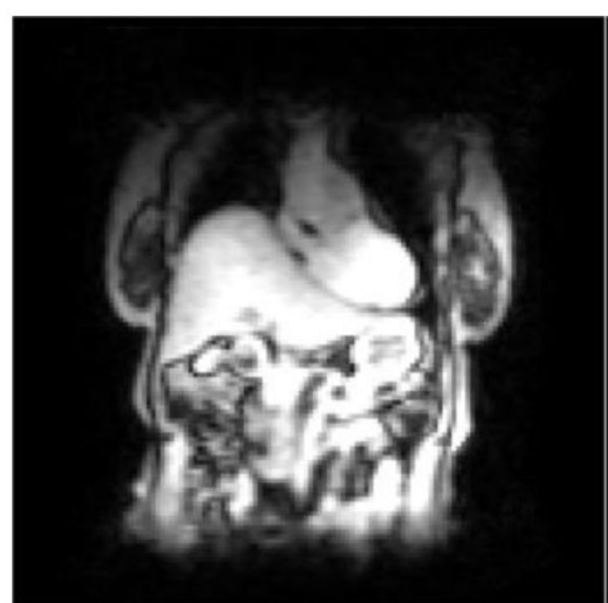

a) Single 2D slice

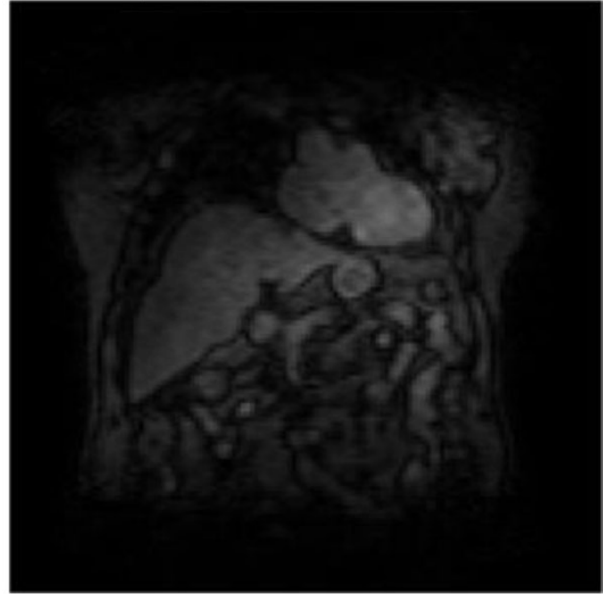

c) Single 2D slice

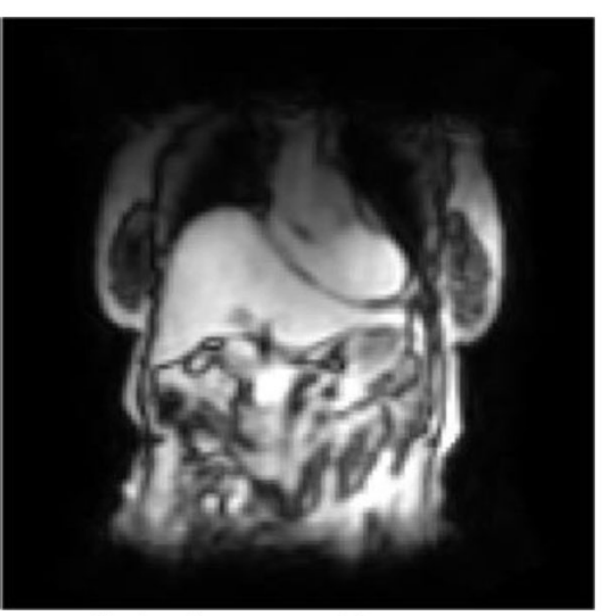

b) Slice from regated dataset

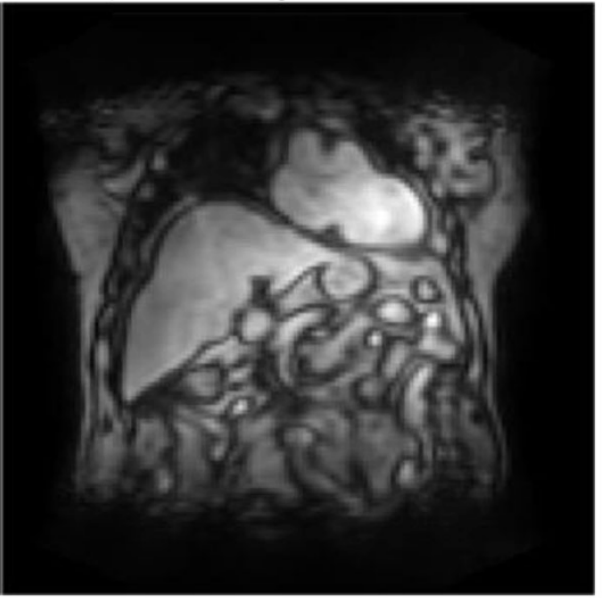

d) Slice from regated dataset

Figure 1 Datasets a) \& c) show 2D slice of two acquired datasets. b) \& d) show a slice from the re-gated, averaged datasets. Note the reduction of noise in the regated dataset.

doi:10.1186/2197-7364-1-S1-A58

Cite this article as: Fieseler et al:: Fast 2D MRI acquisitions for motion correction in PET-MRI. EJNMMI Physics 2014 1(Suppl 1):A58

Submit your manuscript to a SpringerOpen ${ }^{\odot}$ journal and benefit from:

- Convenient online submission

- Rigorous peer review

- Immediate publication on acceptance

- Open access: articles freely available online

- High visibility within the field

- Retaining the copyright to your article

Submit your next manuscript at $>$ springeropen.com 